\title{
Erratum
}

\section{Longitudinal Research at the Interface of Affective Neuroscience, Developmental Psychopathology, Health and Behavioral Genetics: Findings from the Wisconsin Twin Project - ERRATUM}

Nicole L. Schmidt, Rebecca J. Brooker, Ian C. Carroll, Jeffrey R. Gagne, Zhan Luo, Mollie N. Moore, Elizabeth M. Planalp, Katherine L. Sarkisian, Cory K. Schmidt, Carol A. Van Hulle, Kathryn Lemery-Chalfant and H. H. Goldsmith

doi.org/10.1017/thg.2019.55, Published online by Cambridge University Press, 09 September 2019

This article was published in Twin Research and Human Genetics with one of the author names, Mollie N. Moore, missing. This has since been rectified per the above.

\section{Reference}

Schmidt, N., Brooker, R., Carroll, I., Gagne, J., Luo, Z., Moore, M., Planalp, E., Goldsmith, H. (2019). Longitudinal Research at the Interface of Affective Neuroscience, Developmental Psychopathology, Health and Behavioral Genetics: Findings from the Wisconsin Twin Project. Twin Research and Human Genetics, 22(4), 233-239. doi: 10.1017/thg.2019.55 